University of Northern lowa

UNI ScholarWorks

Graduate Research Papers

Student Work

2007

\title{
Assistive technology : an instructional tool to assist college students with written language disabilities
}

Isandra Martinez-Marrero

University of Northern lowa

Let us know how access to this document benefits you

Copyright (C2007 Isandra Martinez-Marrero

Follow this and additional works at: https://scholarworks.uni.edu/grp

Part of the Curriculum and Instruction Commons, Educational Technology Commons, and the Special Education and Teaching Commons

\section{Recommended Citation}

Martinez-Marrero, Isandra, "Assistive technology : an instructional tool to assist college students with written language disabilities" (2007). Graduate Research Papers. 1130.

https://scholarworks.uni.edu/grp/1130

This Open Access Graduate Research Paper is brought to you for free and open access by the Student Work at UNI ScholarWorks. It has been accepted for inclusion in Graduate Research Papers by an authorized administrator of UNI ScholarWorks. For more information, please contact scholarworks@uni.edu. 


\title{
Assistive technology : an instructional tool to assist college students with written language disabilities
}

\begin{abstract}
In their practice, instructional designers develop instructional materials and learning environments that address the individual needs of learners. However, little research has been conducted on how to address the needs of learners with disabilities, especially in post-secondary education. The purpose of this literature review is to explore the literature regarding the use of Assistive Technology as an instructional tool to assist college learners with written language disabilities. Implications for instructional designers are presented.
\end{abstract}




\author{
A Graduate Review \\ Submitted to the \\ Division of Instructional Technology \\ Department of Curriculum and Instruction \\ In Partial Fulfillment \\ Of the Requirements for the Degree \\ Master of Arts \\ UNIVERSITY OF NORTHERN IOWA
}

by

Isandra Martínez-Marrero

January, 2007 
This Review by: Isandra Martínez-Marrero

Titled: ASSISTIVE TECHNOLOGY: AN INSTRUCTIONAL TOOL TO ASSIST

COLLEGE STUDENTS WITH WRITTEN LANGUAGE DISABILITIES

has been approved for meeting the research requirement for the degree of

Master of Arts.

\section{Jan. 12, 2007}

Date Approved

$01-12 \cdot 07$

Date Approved

$01-16-07$

Date Approved
J. Ana Donaldson Graduate Faculty Reader

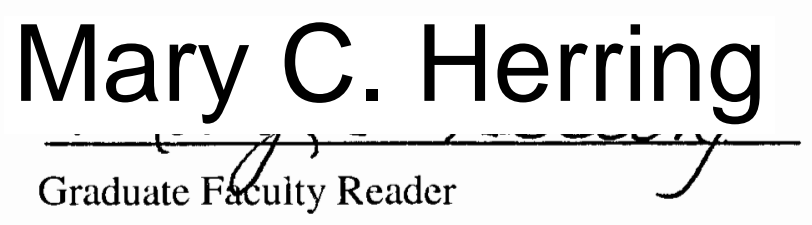

\section{W. P. Callahan}

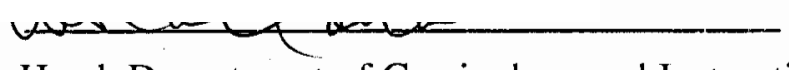

Head, Department of Curriculum and Instruction 


\begin{abstract}
In their practice, instructional designers develop instructional materials and learning environments that address the individual needs of learners. However, little research has been conducted on how to address the needs of learners with disabilities, especially in postsecondary education. The purpose of this literature review is to explore the literature regarding the use of Assistive Technology as an instructional tool to assist college learners with written language disabilities. Implications for instructional designers are presented.
\end{abstract}




\section{TABLE OF CONTENTS}

INTRODUCTION

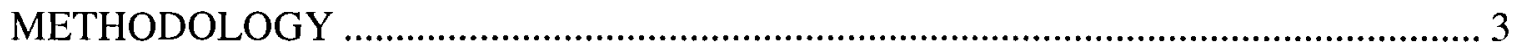

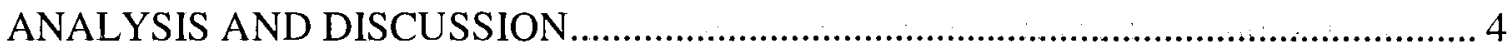

Assistive Technology Overview .................................................................................... 4

Assistive Technology as Legal Mandate ................................................................ 4

Assistive Technology Act ............................................................................... 5

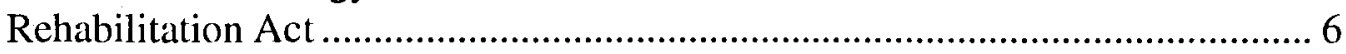

The Dimensions of Assistive Technology ............................................................... 7

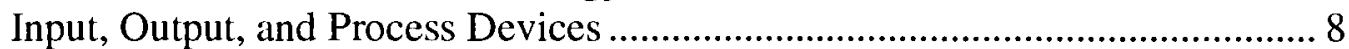

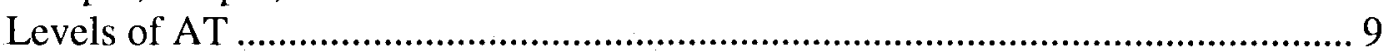

Needs of College Students with Learning Disabilities ................................................... 10

What is a Learning Disability? ............................................................................... 10

Needs of College Students with Learning Disabilities ...................................... 12

Using Assistive Technology as an Instructional Tool ........................................... 14

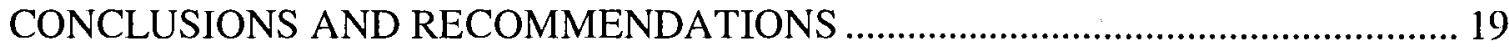

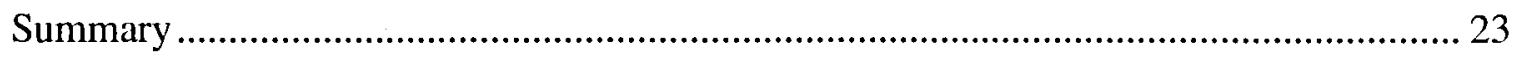

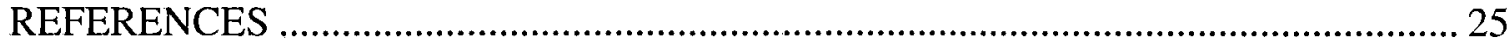




\section{INTRODUCTION}

Professionals in the field of education are emphasizing post-secondary education as the other transition for students with disabilities (Sitlington, 2003). Reports from the National Center for Educational Statistics (Li \& Hamel, 2003; U.S. Department of Education, 2003), indicated that during the academic year 1999-2000, nine percent of all undergraduate students enrolled in post-secondary institutions reported having different types of disabilities that created challenges for them as college students. Of the students with disabilities, $11 \%$ were students with Learning Disabilities or Attention Deficit Disorder. For the purpose of this review learning disability is defined as "a generic term that refers to a heterogeneous group of disorders manifested by significant difficulties in acquisition and use of listening, speaking, reading, writing, reasoning, or mathematical abilities, or of social skill" (NIFL, 2002, p.2). Although literature is accumulating about the integration and use of Assistive Technology in educational settings, the major emphasis has been in the area of K-12 education (Male, 2003; Ulman, 2005) as opposed to post-secondary education. The term Assistive Technology refers to the application of science, engineering, and other disciplines that result in process, methods, or inventions that support persons with disabilities (Bryant \& Bryant, 2003).

Considering the documented role of Assistive Technology in facilitating educational opportunities for students with disabilities in $\mathrm{K}-12$ educational settings (Bryant \& Bryant, 2000; Male, 2003) and the traditionally reported low employment outcomes of persons with disabilities (Frank \& Sitlington, 2000); it seems appropriate for instructional designers to assess their knowledge of Assistive Technology and its use as an instructional tool to assist postsecondary students with disabilities. The purpose of this 
review is to explore the literature regarding the use of Assistive Technology as an instructional tool to assist college students with written language disabilities.

As instructional designers, one of the main considerations of any instructional design effort must be to address the needs of the target audience (Dick, Carey, \& Carey, 2001). Instructional design efforts should be learner-centered (Gustafson, \& Branch, 2002). Through Assistive Technology, persons with disabilities maximize their abilities and are able to perform at levels demonstrated by individuals without disabilities (Bryant \& Bryant, 2000). By designing instruction that considers the use of Assistive Technology as an instructional tool for postsecondary students with written language disabilities, one can foster more mainstream educational opportunities for these students and enhance their abilities of achieving positive postsecondary education. The following questions are posed as the guiding structure for this literature review:

a) What is Assistive Technology and how can it be used to facilitate the learning process of college students with written language disabilities?

b) What are the main educational needs of college students with written language disabilities?

The next section will describe the methodology used to identify and validate the literature for this review. 


\section{METHODOLOGY}

This review will explore the literature on the foundations of Assistive Technology and its use as an instructional tool to assist college students with written language disabilities. To identify the resources for this literature review, various online databases were used such as: (a) ERIC, (b) PsychInfo, (c) EBSCOhost, (d) Electronic Journals Service, and (e)Wilson Web. Both the University of Northern Iowa's Rod Library and the University of Iowa's Main and Psychology Libraries were used to conduct manual searches of other potential sources not identified in the computer-database search.

Various key-words/descriptors were used to find the sources used in this literature review. These were: (a) Assistive Technology, (b) adult education, (c) students with disabilities, (d) learning disabilities, (e) written language disabilities, (f) postsecondary education, (g) computer assisted instruction, (h) multimedia materials, (i) instructional design, (j) uses of Assistive Technology in education, (k) postsecondary adult learning, (l) design considerations, (m) education and employment outcomes, (n) educational needs, and (o) technology interventions. The articles and book chapters identified in the search process were selected based on the sources' relevance to the topic covered in this literature review. The information included in this literature review was evaluated based on the quality of the content, the relevance to the topic, the source of the article (type of journal or book), and the year published. The next section will present the findings and synthesis of the literature identified for this review. 


\title{
ANALYSIS AND DISCUSSION
}

\author{
Assistive Technology Overview
}

"For people without disabilities, technology makes things easier, for people with disabilities technology makes things possible" (Bryant \& Bryant, 2003, p. 2). Literature regards the terms Assistive Technology and Assistive Technology device as synonyms. However, Bryant and Bryant (2003) indicated that Assistive Technology (AT) is the application of science, engineering, and other disciplines that result in process, methods, or inventions that support persons with disabilities. According to the Technology-Related Assistance for Individuals With Disabilities Act of 1988 (U.S. Congress, 1988), an Assistive Technology (AT) device is defined as any item, piece of equipment, or product system, whether acquired commercially or off the shelf, modified or customized, that increases, maintains, or improves functional capabilities of individuals with disabilities. Together, these two definitions emphasize what it is, how it is made, and the intended use of the technology. Today, and in accordance with many laws, AT services are provided to many individuals with disabilities in their personal, educational, and employment environments.

\section{Assistive Technology as Legal Mandate}

Within the past few years, the U.S. Congress has passed several pieces of legislation that greatly improve the civil rights of persons with disabilities, and provide access to assistive and conventional technologies as well (ATA, 2000). This section will provide a brief overview of the legal mandates that enforce the provision of Assistive Technology services for persons with disabilities in their personal, educational, and work 
environments. These legal mandates are: Assistive Technology Act, The Individuals with Disabilities Education Act, The Americans with Disabilities Act, Rehabilitation Act, and the Telecommunications Act. Assistive Technology Act

Signed in 1988, the Assistive Technology Act (Tech-Act) provides federal funds to assist in developing available consumer-responsive systems for access to AT, technology services, and technology information (ATA, 2000; Bryant \& Bryant, 2003). The Tech-Act was the first piece of legislation to provide the definition of AT, the definition used by subsequent and current legislation, and also was the first law to emphasize a consumer-responsive approach; an approach that emphasizes the creation of programs that are specifically designed to address the needs of individuals with disabilities through the use of AT. According to the ATA (2000) this mandates that statedeveloped systems must, at minimum, have in place a process for evaluating and responding to the needs of persons with disabilities. In addition, the Tech-Act diminishes barriers that persons with disabilities may experience in accessing AT. In this regard, AT programs or initiatives under this law, are charged with identifying or disseminating information on different resources and economic programs to purchase AT devices. Individuals with Disabilities Education Act

The Individuals with Disabilities Education Act (IDEA) is the amended version of the Education for All Handicapped Children of 1975. Signed in 1997, the IDEA conslitutes an education act that provides financial support to state and local education agencies. The main focus of IDEA is to guarantee educational services for children with disabilities. Children in the age range of 3 to 21 years, who require special education 
services due to a disability are considered covered under this law (ATA, 2000; Bryant \& Bryant, 2003). Regarding AT, the IDEA identifies the provision of AT services to students with disabilities as a resource to minimize their functional limitations, maximize their functional abilities, and as a factor that facilitates transition for school-aged children with disabilities (ATA, 2000).

Americans with Disabilities Act

The 1990 Americans with Disabilities Act (ADA) is a civil rights law that prohibits discrimination on the basis of disability in employment, public services, and accommodations (ATA, 2000). Any individual who has a disability (physical, cognitive, emotional, developmental, etc.) that limits his/her daily life activities is considered covered under this law. One of the most important rights legislated by the ADA is the requirement that an employer with 15 or more employees may not discriminate on the basis of disability, when the person is qualified to perform the essential functions of the job with or without reasonable accommodation (ATA, 2000). Reasonable accommodation is defined in the ADA as any modification in the job's tasks, structure, or workplaces (i.e. the use of an AT device) that will enable a qualified person with a disability to perform in the employment setting.

\section{Rehabilitation Act}

Authorized in 1973 and last amended in 1992, the Rehabilitation Act was the first law to prohibit discrimination on the basis of disability in employment, within public and government settings (ATA, 2000). This law is responsible for the creation of vocational rehabilitation and independent living services for individuals with disabilities. Under the Rehabilitation Act there are several sections that grant access to services, buildings, 
transportation, and social events to individuals with disabilities in all settings funded by the federal government. In regards to technology, Section 508 ensures that persons with disabilities have access to all the media produced and funded by the federal government (ATA, 2000).

\section{Telecommunications Act}

The 1996 Telecommunications Act can be seen as an extension of Section 508 of the Rehabilitation Act (ATA, 2000). Both have an emphasis on ensuring that persons with disabilities have access to electronic media. However, the Telecommunication Act is also responsible for the emphasis made on screen captioning, alternative tags as descriptors of images on the Web, and the development of measures that make web-based content available to persons with various disabilities. In 1999 the Federal

Communications Commission's Access Board made accessible a final document that describes the technological considerations on making electronic media accessible (AT, 2000). Today these guidelines are fully enforced. Information about these guidelines can be found at http://www.access-board.gov/.

\section{The Dimensions of Assistive Technology}

Thousands of technological devices available on the market can be classified under the umbrella of Assistive Technology (ATA, 2000). These items range from input devices such as large print keyboards to sophisticated output devices like Braille embossers (printers). This section is intended to describe the dimensions of AT. The discussion will range from the types of devices on which AT operates to the different categories and levels of technology in which AT devices are classified. 
Input, Output, and Process Devices

Input, output, and process devices are the first layer of the dimensions of Assistive Technology. Input devices are those responsible for allowing an individual to enter and manage a computer device. Examples of input devices are: standard or large print keyboards, voice recognition or pointing systems, track balls (type of mouse), and touch-screen devices (ATA, 2000; Bryant \& Bryant, 2003). Output devices are those responsible for visual, audio, or printed enhancements. Examples of output devices are: (a) screen magnification, (b) screen or document reading, (c) large print, or (d) Braille embossers (ATA, 2000; Bryant \& Bryant, 2003). Process devices are responsible for allowing a user easy operation of the device and information processing. Examples of process devices include key-combination "hot keys", programs designed to facilitate skills like writing, keyboarding, reading, or programs designed for organization of ideas, themes, and concepts (ATA, 2000).

These input, output, and process devices can be further classified into what Bryant and Bryant (2003) calls the 7 Categories of Assistive Technology (p. 4). These are:

1. Positioning, which refers to those AT devices that help a person achieve or maintain certain position in the performance of different activities.

2. Mobility, included in this category are those devices that enable a person to move in various environments.

3. Augmentative Communication, which refers to those AT devices that assist persons with speech difficulties in developing and facilitating their communication skills. 
4. Computer Access, this category includes all those AT devices and programs that allow a person to fully use a computer system without restrictions.

5. Adaptive Toys and Games, included in this category are those toys and games that are used to explore, measure, and develop social and cognitive skills of children with disabilities.

6. Adaptive Environments, which refer to AT devices that allow a person with a disability the control over his/her environment to facilitate independent living, working, studying, playing etc. and

7. Instructional Aids, which refers to those materials, devices, or programs that facilitate educational skills in students with disabilities.

Considering that this literature review will focus on the population of students with learning disabilities in the area of writing, this last AT category will be further referenced in later topics.

\section{Levels of AT}

Assistive Technology may be described by its level, which is generally a correlation between the technological difficulty of the device and the level of technical training the person needs to make effective use of the device (Roy, 2003; Weiland, 2003). First, AT No-tech solutions are those that make use of procedures, services, and existing conditions in the environment and do not involve the use of devices or equipment. Examples could include pencil grips, colored paper, and extra time for testing, and the use of a scribe or reader (Roy, 2003; Weiland, 2003). Low-tech items are less sophisticated and can include devices such as adapted spoon handles, non-tipping drinking cups, calculators, tape recorders, magnifiers, and Velcro fasteners. Medium-tech devices are relatively 
complicated mechanical devices, such as wheelchairs. Lastly, High-tech devices incorporate sophisticated electronics or computers-type technologies (ATA, 2000; Bryant \& Bryant, 2003; Roy, 2003).

\section{Needs of College Students with Learning Disabilities}

Thus far, this literature review has defined Assistive Technology and explained its role as a legal mandate. Devices categorized as Assistive Technology (AT) were also described and its relation to the seven AT categories explained. The following section and the remainder of this literature review will introduce the role AT has in the learning process of students with learning disabilities in the area of writing. The review will also provide a discussion on the use of Assistive Technology as an instructional tool to assist college students with written language disabilities. This section will first define the term learning disability and explain the educational needs of adults with learning disabilities based on the findings of this literature review.

\section{What is a Learning Disability?}

As a result of the increasing and changing demands seen in the workplace during the last decade, more attention has been given to adults with learning disabilities. This attention shift is greatly attributed to the fact that most people do not outgrow learning disabilities (LD Online, 2001). Several definitions are found in the literature given that professionals have not been able to reach a consensus regarding what is a learning disability. Some common elements among the definitions suggest that learning disabilities exist when a person has uneven developmental patterns, problems in the central nervous system, or interference in their neurological processes. Other definitions 
suggest that problems involving understanding spoken or written language, academic achievement, or social skills might be manifestations of learning disabilities (LD Online, 2001; NIFL, 2002).

For the purpose of this literature review, the reviewer has chosen the definition provided by the Interagency Committee on Learning Disabilities. This committee states that a learning disability "is a generic term that refers to a heterogeneous group of disorders manifested by significant difficulties in acquisition and use of listening, speaking, reading, writing, reasoning, or mathematical abilities, or of social skill" (NIFL, 2002, p. 2). These disorders are intrinsic to the individual and are presumed to be due to a central nervous system dysfunction. Even though learning disabilities may appear in tandem with other disabilities that may cause learning problems (i.e. attention deficit disorder), a learning disability is not the direct result of those conditions (NIFL, 2002). The Individuals with Disabilities Education Act (IDEA) states that a learning disability is not the direct result of visual, motor, or hearing disabilities, neither are they the result of environmental, cultural, or economic disadvantage (Li \& Hamel, 2003).

Learning disabilities, as a lifelong condition, may impact individuals in various aspects of their life. Self esteem may be affected due to a perceived failure in academic and social activities. Vocational problems may arise due to learning disabilities that causes organizational, scheduling, and language expression difficulties (Li \& Hamel, 2003). In terms of social interactions, adults with learning disabilities may seem less sensitive to other's feelings and have trouble discriminating social responses. Lastly, learning disabilities can impact individuals' educational experiences by posing difficulties in areas such as spoken and written language, arithmetic, reasoning, and 
organizational skills (NIFL, 2002). Given the broad scope of the literature describing the needs of students with learning disabilities, this literature review will focus in more detail on the writing issues of these students in postsecondary education settings.

\section{Needs of College Students with Learning Disabilities}

As mentioned earlier, learning disabilities can impact individuals by creating difficulties in areas such as reading, listening, arithmetic, reasoning, organization, and writing (LD Online, 2001; NIFL, 2002). In a college environment, these skills are linked to a majority of the tasks students will need to perform in order to succeed. Writing, in particular, poses its own unique and intense demands on students with learning disabilities (Norton, 1992). Research on college students with learning disabilities underlines difficulties in both the mechanical and contextual aspects of writing ( $\mathrm{Li} \&$ Hamel, 2003). Difficulties in the mechanical aspects of writing involve issues in spelling, punctuation, and capitalization. Also, difficulties in the content aspects of writing are related to a lack of organization and coherence (Higgins \& Zvi, 1996; Li \& Hamel, 2003; Sills, 1995).

Various studies conducted during the 1990's suggest that writing represents a major challenge for students with learning disabilities (MacArthur, 1996; Norton, 1992). Such a conclusion has been the product of comparisons among the written language tasks performance of students with and without learning disabilities. The main difficulties associated with these tasks were related to "the physical demands and conventions of writing and with fluent production of sentences" (MacArthur, 1996, p. 1). Other skills involving the generation, organization, and evaluation of the written content also represented a challenge for the students with learning disabilities. 
Other researchers (e.g. Lauffer, 2000; Newcomer \& Barenbaum, 1991) described the major writing needs of students with learning disabilities in postsecondary education. These include but are not limited to:

- lack of cohesiveness;

- difficulties in text production, planning, and editing;

- superficial revisions involving spelling and punctuation;

- difficulties in the generation of ideas, maturity of themes, organization, grammar, and theme development.

In addition, Lauffer noted that students with writing difficulties presented limited memory search and retrieval skills, and have difficulty categorizing and ordering information. At the college level, the above mentioned skills are not only valuable, but in many cases needed to prove mastery of a subject (e.g. research papers, comprehensive exams, reading summaries, or online discussion postings).

During the last decade few empirical studies have been devoted to the writing skills of post-secondary students with learning disabilities. However, the studies available have observed significant spelling, punctuation, and capitalization errors in documents created by students with learning disabilities. Gregg, Hoy, McAlexander, and Hayes (1991), suggested that these error patterns may be related to a cognitive processing deficit that inhibits the individual's ability to learn or apply sentence construction or punctuation rules. Another major difficulty for these students relates to the lack of cohesiveness on written work. The following section will describe the use of Assistive Technology as an instructional tool to assist postsecondary students with written language disabilities. 


\section{Using Assistive Technology as an Instructional Tool}

Currently, national legislation emphasizes the importance of increasing student achievement in order to improve the quality of education in the United States (Bryant \& Bryant, 2003). For many students with disabilities, obtaining an education represents a challenge given the difficulties associated with accessing, learning, or performing in the required content areas. In postsecondary education, Assistive Technology represents a tool that assists students with learning disabilities to succeed in their academic endeavors (Mull \& Sitlington, 2003). Assistive Technology can enhance the individual's learning abilities by circumventing deficits. According to Rivera and Smith (1997), AT can be used to provide services based on two rather complementary approaches. On the one hand, compensatory adaptations attempt to circumvent a problem and offer a solution to enhance access. For instance, allowing a student, with a reading disability, to use a textto-audio program to study his or her literature textbooks in order to facilitate reading comprehension. On the other hand, remedial adaptations are techniques that attempt to correct a problem after other techniques have proven to be ineffective (Rivera \& Smith, 1997). An example of this type of adaptation would involve providing the student of the literature class with a printed version of the textbook, in addition to the text-to-audio program, in order to visually familiarize him or her with difficult or unlearned vocabulary.

Considering the high percentage of adults with learning disabilities that exhibit writing disorders (Day \& Edwards, 1996), and the increasing number of students with learning disabilities in postsecondary education (Li \& Hamel, 2003; U.S. Department of Education, 2003), it is not surprising that some researchers have focused their work on 
the role of AT on the written language difficulties of these students in postsecondary education. Several technologies are currently available to support the learning needs of students with written language difficulties. Word processors, for instance, are among the technologies most mentioned by researchers in the AT field (Bryant \& Bryant, 2003; Day \& Edwards, 1996: Li \& Hamel, 2003; MacArthur, 1996). Word processors such as Talking Word Processor (Premier Assistive Technology, 2006) have editing, spell checking, a dictionary, a thesaurus, and proofreading features that facilitate the student's revision of his/her written work. This particular technology also has a motivational effect on students with writing disabilities; it allows them to produce neat and grammatically correct printed documents. Contrarily, researchers suggest that when students with writing difficulties are required to handwrite, they may experience frustration and feel more challenged by this process (Catkins, 1991).

Outlining software is another AT tool that can be used to support the needs of college students with written language disabilities. Regardless of expertise, outlining and brain storming are practices used by writers to organize their ideas before writing (MacArthur, 1996). Outlining software, such as Inspiration (Inspiration Software, 2006), allows learners to create brain storming maps that can be easily rearranged as new ideas emerge. After completion, students can convert their brain storming map into an organized outline with the touch of a button. In a recent article, Blankfield and Williams (2003) reported their use of Inspiration as a tool to develop the academic writing skills of students with Dyslexia. These researchers pointed out several features of this software, such as the use of color, shape, and spatial distribution, as important cognitive organizing 
tools, helping students with Dyslexia to customize their approach to planning written texts (Blankfield \& Williams, 2003).

Technical advances in the area of speech recognition are also making a difference in the performance of postsecondary students with writing difficulties. Speech recognition has become one of the most used tools for postsecondary students with writing difficulties (Li \& Hamel, 2003). An example of this technology is Scan Soft's (2006) Dragon Naturally Speaking. The methodology behind speech recognition is to tap into presumed oral/verbal vocabulary and skills of the student and therefore escape the writing difficulties of the student and their reliance on other more dependent-type supports such as scribes (Higgins \& Raskind, 1995, p. 160). According to Disability Services in Higher Education (2006), a scribe is a person who transcribes what a person with a writing disability says out loud. Given the concern expressed by researchers on the writing performance of college students with learning disabilities, the following section will describe examples of various studies on the use of AT to support the writing needs of students with learning disabilities.

Collins (1990) studied the effects of word processing programs in assisting college students with learning disabilities. During a three-year period a total of 57 students, both students with and without disabilities and writing difficulties, participated in a college introductory writing course. This course was delivered in a computer supported room. The effects of the AT intervention were measured by comparing both groups on their course completion rates; grades, writing fluency, and change in attitudes toward writing (Collins, 1990). Results indicated that there was not a significant difference between the two groups in their completion rates and grades. This finding 
suggests that the AT successfully assisted students with writing difficulties in their academic achievement. In addition, results indicated that even if writing apprehension in the students with writing difficulties decreased, they still demonstrated significantly more grammatical errors than did students without disabilities (Collins, 1990). The researcher emphasized the role of AT in developing the self-confidence of these students with writing difficulties while avoiding the anxiety experienced in paper-pencil exercises.

Using another approach to AT, Higgins and Raskind (1995) evaluated the written compositions of 29 postsecondary students. The students were required to provide a written sample (essay) performed under three conditions: 1) using a scribe; 2) without any assistance; and 3) using a speech recognition program. The researchers used various measures of fluency, vocabulary, and syntax to analyze the results (Higgins \& Raskind, 1995). Results indicated that the students received higher scores on their essays using the speech recognition software. Researchers suggested this indicates the use of the speech recognition program encouraged the students in using more elaborate and proficient writing styles.

More recently, Li and Hamel (2003) conducted a 10-year review of the literature on Assistive Technology (AT) for postsecondary students with writing needs. From their qualitative analysis, reviewed articles were categorized as providing an overview of AT, describing research on the effectiveness of AT, and discussing AT as instructional support. Regarding research on the effectiveness of AT, only 10 studies were identified between the years of 1990 and 2000 . These studies were conducted in the areas of using word processors and speech recognition software to enhance writing skills, writing error patterns, spelling, punctuation, capitalization, coherence errors, and gender differences. 
In their conclusions, the authors indicated that more research is needed in the use of AT to support the writing needs of postsecondary students with writing difficulties. Future research should focus on those factors that internally may have an effect on the writing skills of these students (e.g. motivation, anxiety, support), rather than focusing on the effect of the provision of the AT intervention (Li \& Hamel, 2003).

So far in this literature review the researcher has presented an overview on the foundations of Assistive Technology as well as its role as a legal mandate. Several pieces of legislation such as the Assistive Technology Act, the Americans with Disabilities Act, and the Rehabilitation Act were briefly discussed. Literature that supports the use of AT as an instructional tool and its role in promoting positive educational outcomes for students with written language disabilities were also presented. Based on the reported benefits of AT in meeting the needs of college students with written language disabilities, it would be important to analyze how this applies to the field of Instructional Design. The next section will discuss the conclusions and recommendations of this review and will also provide some general recommendations for Instructional Designers. 


\section{CONCLUSIONS AND RECOMMENDATIONS}

The purpose of this literature review was to explore the use of Assistive Technology as an instructional tool to assist college students with written language disabilities. More specifically this review aimed to explore what is Assistive Technology, how it can be used to facilitate the learning process of college students with written language disabilities, and what are the main educational needs of these individuals.

Literature on the area of AT and written language disabilities defines the term Assistive Technology as the application of science, engineering, and other disciplines that result in process, methods, or inventions that support persons with disabilities. Research on these areas also discusses the challenges that several aspects of written composition represent to college students with written language disabilities and highlights the proven role of AT in supporting the needs of these individuals. Some of the challenges presented in the literature refer to the students' lack of cohesiveness in their written work and to their difficulties generating, evaluating, and organizing written content. Also, there are studies that document the positive outcomes of the use of different AT devices, such as voice recognition, concept-organization, and scan and read programs, to aid students with written language disabilities in their educational endeavors. Thus, it seems a logic step for teachers and instructional design professionals to be informed on the area of AT.

Dick, et al (2001) stated that as instructional designers, one of the main considerations of any instructional design effort must be to address the needs of the target audience. Moreover, Gustafson, \& Branch (2002) stated that these efforts should be learner-centered. These premises however should accommodate learners in all levels of development and abilities. As professionals, instructional designers work in a variety of 
settings with businesses and postsecondary institutions their main employers. Reiser (2002) stated that most instructional design positions are found in business and industry. In this environment, instructional designers work as corporate trainers, project managers, course designers, developers, and more. At postsecondary institutions, instructional designers may have similar roles, but their work is aimed at a different audience.

With the introduction of computers at postsecondary institutions, the increased advocacy for its use to support learning, and the greater demand to fulfill the needs of a wide variety of learners, instructional designers have become consultants for faculty and students. In this role, instructional designers could actively assist faculty members in the development of curriculum and courses that consider the use of AT as an instructional tool to assist all learners, including those with written language disabilities.

Inclusion of AT in postsecondary education to address the needs of students with disabilities has increased during the last few years (Michaels, Pollock, Morabito, \& Jackson, 2002). Moreover, researchers have recognized the potential benefits of AT for these students with disabilities (Blankfield \& Williams, 2003; Collins, 1990; Higgins \& Raskind, 1995; Mull \& Sitlington, 2003). Yet the exploration of the use of AT in the instructional design field has not been fully explored. Given the specialized education of instructional designers in developing educational environments and materials to attend the individual needs of their audience, it seems only logical that infusing AT into their practice will assist these professionals in producing educational materials or environments receptive to the needs of persons with disabilities in a variety of settings.

Providing instructional designers with some general considerations regarding the inclusion of AT into their practice would represent a starting point in expanding the 
knowledge base of these professionals. Based on the completed literature review, the following considerations are presented as general guidelines that address what instructional designers should consider when designing instructional materials that propose the use of AT as an instructional tool to assist learners with written language disabilities:

- Become AT savvy. The Rehabilitation Engineering Society of North America (RESNA) (www.resna.org), leader organization in the AT field, can be a starting point in becoming familiar with AT concepts, funding sources, and assessment procedures. A wide variety of books and online educational materials are also available in libraries and the Internet. In addition, California State University offers an annual conference (CSUN) were the latest AT topics are presented by experts from across the nation. Practice in integrating instructional design and AT concepts will eventually lead you to becoming proficient and comfortable with the inclusion of AT in the design of instruction.

- Make it worth the effort. Work in collaboration with a content expert in the area of learning disabilities and/or Assistive Technology specialist to ensure that your design meets the basic needs of the learners. This may prove to be an enlightening experience for all involved.

- Focus on strengths. Develop an instructional strategy that reflects a complete analysis and understanding of the learners' characteristics and learning style. Develop flexible instructional strategies that can be adjusted according to the 
students' strengths. Recognize the students' disabilities and learn about their impact in the educational, social, and personal environments.

- Ensure AT availability and explore the built-in capabilities of the existing hardware. When defining technical requirements, specify the AT applications that would best support the instructional needs of the student with written language disabilities. In this task support from an AT specialist or from the university’s Disability Services Office maybe needed. Ensure the recommended AT applications or devices are or will be available to the learners when needed. If not available or own by the learner, explore the builtin capabilities of the existing hardware.

- Training needed? Find answers for the following questions: Is the AT device/application new to the learner or is he/she an experienced user? Is training needed? Who will provide it? If needed, who will provide technical support?

- Built-in flexibility. Design with flexibility in mind. How can the sequence/pace of the course be modified to best support the learners' needs and the use of the AT device/application?

- Evaluate, do not assume. Assess student performance and comfort level with the course format, sequencing, and AT device/application chosen. In addition to traditional evaluation strategies (i.e. papers, essays), what other evaluation strategies can be implemented to assess the performance of college students with written language disabilities? Modify the instructional strategies/tools if needed and reevaluate. 


\section{SUMMARY}

The purpose of this review was to explore the literature regarding AT as an instructional tool to assist college students with written language disabilities. An overview of AT was provided along with some general constructs. In becoming more knowledgeable about AT, more accessible educational programs and environments can be developed that may translate in more positive educational outcomes for this population. Is important that instructional designers acknowledge the role Assistive Technology has in maximizing the abilities of persons with disabilities. Various research studies were discussed that supported the role of AT in this conclusion. By designing instruction that considers the use of Assistive Technology for postsecondary students with written language disabilities, we as instructional designers and instructors can foster more mainstream educational opportunities for these students and enhance their abilities of achieving positive postsecondary education, which may translate in better occupational outcomes in the future.

Researchers in the field of instructional design should consider exploring more Assistive Technology in their research projects. Considering the reported effects of AT in the educational process of students with written language disabilities it would be important to further explore how instructional designers can incorporate AT and related constructs within their practice. Lastly, instructional design educators should consider infusing more disability and AT content in their curriculum. Knowledge in these content areas will not only prepare their students on how to best address the needs of learners with various ability levels, but it will also provide them with a better picture of the wide 
array of professional environments where they can apply what they have learned during their college years. 


\section{REFERENCES}

Alliance for Technology Access, ATA. (2000). Current laws and legislation. In Alliance for Technology Access (Eds). Computer and web resources for people with disabilities: A guide to exploring today's Assistive Technology. CA: Hunter House.

Blankfield, S., \& Williams, S. (2003). Dyslexia, 'Inspiration' and academic writing. Cognitive Processing, 4, 22.

Bryant, D. P., \& Bryant, B. R. (2000). Assistive Technology for people with disabilities. CA: Allyn and Bacon.

Catkins, L.M. (1991). Living between the lines. Portsmouth, NH: Heineman.

Collins, T. (1990). The impact of micro-computer word processing on the performance of learning disabled students in a required first year writing course. Computers and Compositions, 8, 49-68.

Day, S. L., \& Edwards, B. J. (1996). Assistive Technology for postsecondary students with learning disabilities. Journal of Learning Disabilities, 29(5), 486-492.

Dick, W., Carey, L., \& Carey, J.O. (2001). The systematic design of instruction $\left(5^{\text {th }} E d\right)$. NY: Addison-Weley.

Disability Services in Higher Education. (2006). Scribes. Retrieved on June 26, 2006, from http://www.disabilityresource.uic.edu/viewer.asp?tab=4\&label=Scribes

Frank, A. R., \& Sitlington, P. L. (2000). Young adults with mental disabilities: Does transition planning make a difference? Education and Training in Mental Retardation and Developmental Disabilities, 35(2), 119-134. 
Gregg, N., Hoy, C., McAlexander, P., \& Hayes, C. (1991). Written sentence production error patterns of college writers with learning disabilities. Reading and Writing, $3(2), 169-185$.

Gustafson, K.L., \& Branch, R.M. (2002). What is instructional design? In R.A., Reiser and J.V., Dempsey (Eds). Trends and issues in instructional design and technology. N.J: Pearson Education.

Higgins, E. L., \& Zvi, J.C. (1996). Assistive Technology for postsecondary students with learning disabilities: From research to practice. Annuals of Dyslexia, 45, 123-142.

Higgins, E. L., \& Raskind, M. H. (1995). Compensatory effectiveness of speech recognition on the written composition performance of postsecondary students with learning disabilities. Learning Disability Quarterly, 18(2), 159-174.

Inspiration Software Inc. (2006). Inspiration. Retrieved on April 4, 2006, from http://www.inspiration.com/.

Lauffer, K.A. (2000). Accommodating students with specific writing disabilities. Journalism and Mass Communication Educator, 54(4), 29-46.

LD Online (2001). Adults with learning disabilities. Retrieved on March 4, 2006, from http://ldonline.org/ld_indepth/adult/eric189.html

Li, H., \& Hamel, C.M. (2003). Writing issues of college students with learning disabilities: A synthesis of the literature from 1990 to 2000. Learning Disability Quarterly, 26, 29-46.

MacArthur, C.A. (1996). Using technology to enhance the writing processes of students with learning disabilities. Journal of Learning Disabilities, 29 (4), 344-354. 
Male, M. (2003). Technology for inclusion: Meeting the special needs of all students. MA: Pearson Education.

Michaels, G.A., Pollock, F., Morabito, S.M., \& Jackson, K. (2002). Assistive and instructional technology for college students with disabilities: A national snapshot of postsecondary service providers. Journal of Special education Technology, 17, $5-14$.

Mull, C. A., \& Sitlington, P. L. (2003). The role of technology in the transition to postsecondary education of students with learning disabilities: A review of the literature. Journal of Special Education, 37(1), 26-32.

National Institute For Literacy (NIFL), 2002. Adults with learning disabilities:

Definitions and issues. Retrieved on March 9, 2006, from http://www.nifl.gov/nifl/ld/archive/definiti.htm

Newcomer, P.L., \& Barenbaum, E.M. (1991). The writing composing ability of children with learning disabilities: A review of the literature from 1980 to 1990. Journal of Learning Disabilities, 24, 578-591.

Norton, S. (1992). Postsecondary learning disabled students. Do their study habits differ from those of their non disabled peers? Community/Junior College Quarterly, 16, 105-115.

Premier Assistive Technology (2006). Talking Word Processor. Retrieved on April 4, 2006, from http://www.premier-programming.com/home.htm.

Reiser, R.A. (2002). Getting an instructional design position: Lessons from a personal history. In R.A., Reiser and J.V., Dempsey (Eds). Trends and issues in instructional design and technology. N.J: Pearson Education 
Rivera, D., \& Smith, D. D. (1997). Teaching students with learning and behavior problems $\left(3^{r d} e d\right)$. Boston: Allyn Bacon.

Roy, J. (2003). Assistive Technology "Low-tech" to "Hi-tech" considerations. Retrieved on April 16, 2006, from http://www.nsnet.org/atc/tools/lowtohightech.html ScanSoft (2006). Dragon Naturally Speaking. Retrieved on April 4, 2006, from http://www.nuance.com/.

Sills, C.K. (1995). Success for learning disabled writers across the curriculum. College Teaching, 43, 66-71.

Sitlington, P. L. (2003). Postsecondary education: The other transition. Exceptionality, 11(2), 103-113.

U.S. Department of Education. National Center for Education Statistics. (2003). The Condition of Education 2003. (NCES 2003-067).

Ulman, J.G. (2005). Making technology work for learners with special needs. MA: Pearson Education.

Weiland, N. (2003). Assistive Technology. Retrieved on April 16, 2006, from http://www.seo-serrc.org/AT.htm, Southeastern Ohio Special Education Regional Resource Center. 